Revista Científica ANAP Brasil

ISSN 1984-3240 - Volume 13, número 29, 2020

\title{
Implicações da Morfologia Urbana na Temperatura Superficial de Pavimentos
}

Implications of Urban Morphology on Surface Temperature of Pavements

Implicaciones de la Morfología Urbana en la Temperatura Superficial de Pavimentos

Luiz Fernando Kowalski

Doutorando, UFSCar, Brasil

fernando.kowalski@ucb.org.br

Ítalo Alberto Gatica Ríspoli

Professor Doutor, UNASP, Brasil. Italo.gatica@gmail.com

Mathews Winston Marques da Paixão

Bacharelado, UNASP, Brasil. math_paixao@hotmail.com

André Mendes Elias Bacharelado, UNASP, Brasil. andre.m.elias26@gmail.com 


\title{
Revista Científica ANAP Brasil
}

\author{
ISSN 1984-3240 - Volume 13, número 29, 2020
}

\section{RESUMO}

A alteração da cobertura natural do solo pelo revestimento asfáltico provoca modificações no microclima das cidades. Por isso, materiais com propriedades térmicas reflexivas favorecem nas condições de conforto urbano, em virtude de valores de temperatura inferiores a materiais não reflexivos. Sendo assim, o objetivo deste trabalho é analisar o comportamento térmico da superfície pavimentada e identificar se há uma correlação entre a Zonas Climáticas Locais (LCZ) e as temperaturas de superfície, a fim de melhorar as condições de conforto e do microclima local. O método se classifica como teórico-experimental e consiste, inicialmente, na caracterização do local e das propriedades do pavimento. A segunda etapa corresponde a aquisição de dados in loco por meio da instalação de sensores de temperatura, umidade relativa do ar, anemômetros e imagens termográficas. Os resultados indicaram que a temperatura superficial asfáltica está associada à quantidade de superfície edificada e impermeável e o que tem mais influência na temperatura do ambiente é a quantidade de sombreamento no ambiente.

PALAVRAS-CHAVE: Morfologia. Pavimento. Temperatura de superfície.

\section{ABSTRACT}

The alteration of the soil's natural cover for asphalt coating causes changes in the microclimate of the cities. Therefore, materials with reflective thermal properties are beneficial in terms of urban comfort, due to their values of temperature being lower than the ones of non-reflective materials. Thus, this work aims to analyze the thermal behavior of the paved surface and to identify if there is a relation between Local Climate Zones (LCZ) and the surface temperatures, in order to improve the conditions of comfort and local microclimate. It used the theoreticalexperimental method, which initially consists in characterizing the place and the pavement properties. The second stage of this paper corresponds to acquiring on-site data, such as installing temperature sensors, relative humidity, anemometers, and thermal images. The results indicated that the asphalt surface temperature is associated with the amount of built up and impermeable surface and what has more influence on the ambient temperature is the amount of shading in the environment.

KEYWORDS: Morphology. Pavement. Surface temperature.

\section{RESUMEN}

La alteración de la cubierta natural del suelo por el revestimiento asfáltico provoca cambios en el microclima de las ciudades. Por lo tanto, los materiales con propiedades térmicas reflectantes favorecen las condiciones de confort urbano, debido a los valores de temperatura más bajos a los materiales no reflectantes. Así, el objetivo de este trabajo es analizar el comportamiento térmico de la superficie pavimentada e identificar si existe una correlación entre las zonas climáticas locales (LCZ) y las temperaturas superficiales, con el fin de mejorar las condiciones de confort y el microclima local. El método se clasifica como teórico-experimental y consiste inicialmente en la caracterización del sitio y las propiedades del pavimento. La segunda etapa corresponde a la adquisición de datos sobre el terreno mediante la instalación de sensores de temperatura, humedad relativa, anemómetros e imágenes termográficas. Los resultados indicaron que la temperatura de la superficie asfáltica está asociada con la cantidad de superficie construida e impermeable y lo que más influye en la temperatura del medio ambiente es la cantidad de sombreado en el medio ambiente.

PALABRAS CLAVE: Morfología. Pavimento. Temperatura de superficie. 


\title{
Revista Científica ANAP Brasil
}

\author{
ISSN 1984-3240 - Volume 13, número 29, 2020
}

\section{INTRODUÇÃO}

A cidade em constante crescimento se depara com a questão da substituição de áreas verdes, por áreas edificadas. E consequentemente com as implicações no microclima, na qualidade do ar e nas condições de conforto térmico.

Segundo Monteiro (2018) essa preocupação se dá devido ao crescimento dos territórios e a influência que a densidade populacional exerce no ecossistema, buscando ao máximo evitar a interferência antropogênica nas condições climáticas locais.

O enfraquecimento do ambiente natural é resultado da forte urbanização, mesmo o Brasil se tornando menos urbano nesta década. De acordo com estimativas para o censo de 2020, a população brasileira nos centros urbanos passou de $84,4 \%$ para $78,4 \%$, sendo o Sudeste a região mais densa geograficamente do território nacional, segundo estudo realizado pelo Instituto Brasileiro de Geografia e Estatística (IBGE, 2017).

Além disso, a grande parcela de zonas pavimentadas nos centros urbanos, aliada à falta de cobertura natural e a mudança de cursos naturais de rios e córregos, são fatores que se relacionam ao crescimento das cidades e que favorecem a mudança de microclima (FRANCO, 2013).

A aglomeração urbana juntamente com o uso diversificado da superfície terrestre ocasiona uma produção de microclimas desconfortáveis para os habitantes, alterando o equilíbrio energético da atmosfera com a Terra, particularmente, nas regiões tropicais continentais, assim, ocorrendo um confinamento do calor em áreas urbanas (GHENO, 2012).

Para Monteiro (2018) esse aprisionamento térmico nos centros urbanos ocorre devido às características físicas dos materiais da superfície e sua resistência em eliminar o calor acumulado. A retenção deste calor aglomerado causa ao usuário um incômodo (CORBELLA e MAGALHÃES, 2008).

Esse desconforto é ocasionado pela diminuição da umidade relativa, aumento da temperatura do ar e a redução da ventilação natural como consequência do aumento da rugosidade no ambiente em questão (MONTEIRO, 2018).

A fim de analisar o ambiente e classificar a região, é necessário levantar algumas informações locais relativas à aplicabilidade e revestimento do solo. A classificação da área de estudo pode ser realizada por meio do método das Zonas Climáticas Locais - Local Climate Zones (LCZ), proposto por Stewart \& Oke (2012).

Monteiro (2018) comentou que ao se empregar e classificar a LCZ, se conhecendo a morfologia e utilidade do solo, é possível distinguir as áreas rurais das urbanas. Os centros urbanos, em grande parte, são cobertos por materiais de cor escura que captam energia solar e liberam calor no ambiente, além da impermeabilidade da superfície, o que acaba dificultando a evaporação da água do pavimento assim prejudicando o resfriamento (NETO, 2015).

Sendo assim, tem por objetivo analisar o comportamento térmico da superfície pavimentada e identificar se há uma correlação entre a Zonas Climáticas Locais (LCZ) e as temperaturas de superfície, a fim de melhorar as condições de conforto e do microclima local. 


\section{Revista Científica ANAP Brasil}

ISSN 1984-3240 - Volume 13, número 29, 2020

\section{REVISÃO BIBLIOGRÁFICA}

\subsection{PROCESSO FÍSICOS DE TROCA DE CALOR}

Segundo Neto (2015) os componentes asfálticos armazenam energia em forma de calor no seu interior através da radiação solar. A radiação solar incidente na superfície terrestre através dos processos físicos de condução, irradiação e convecção, alteram os balanços energéticos e acabam aquecendo o solo e ar, assim aumentando a temperatura do ar (AYOADE, 1991).

No que dize respeito aos processos físicos, deve-se considerar as propriedades radiantes do material, como o albedo e a emissividade. $O$ albedo é refletância total de um sistema, entre o fluxo refletido e incidente, ambos incorporados ao espectro solar (FERREIRA, 2003). E a emissividade $(\varepsilon)$ define o potencial para liberar e absorver energia radiante em ondas longas (DORNELLES, 2008).

Nas coberturas asfálticas o albedo é de $10 \%$ e pode chegar a absorver em torno de $90 \%$ da radiação solar para depois liberá-la (GARTLAND, 2010). Sendo assim, os valores de refletância são mínimos para corpos de coloração escura e máximos para corpos brancos (MENDONÇA \& DANNI-OLIVEIRA, 2007).

$\mathrm{Na}$ Tabela 1 tem-se valores de albedo e a emissividade de materiais que podem ser encontrados em meios urbanos, mas esses valores podem ser influenciados pela densidade, textura e coloração dos materiais.

Tabela 1: Valores de Refletância da Superfície em materiais urbanos

\begin{tabular}{|c|c|c|}
\hline Superfície & Albedo $(\boldsymbol{\rho})$ & Emissividade $(\boldsymbol{\varepsilon})$ \\
\hline Asfalto & $0,05-0,20$ & 0,95 \\
\hline Concreto & $0,10-0,35$ & $0,71-0,90$ \\
\hline Pintura Branca & $0,70-0,90$ & $0,85-0,95$ \\
\hline Grama & $0,15-0,30$ & 0,96 \\
\hline Solo Úmido & $0,10-0,25$ & 0,98 \\
\hline Solo Seco & $0,20-0,40$ & $0,90-0,95$ \\
\hline
\end{tabular}

Fonte: Adaptado de Erell, Pearmutter e Williamson (2010, p. 30).

Além disso, há uma estreita relação entre o processo de troca de calor e o espectro eletromagnético. Para Neto (2015), o calor e a luz solar radiado pela superfície terrestre são as fontes dominantes naturais de energia.

Ferreira (2003) afirmou que a visão humana é sensível a região visível (VIS) do espectro eletromagnético e suas mudanças de frequências, implicam na diferenciação e compreensão das cores que vemos. Esse intervalo está entre os comprimentos de onda de $380 \mathrm{~nm}$ e $780 \mathrm{~nm}$; o que corresponde à $46 \%$ de toda a radiação solar.

Além disso, há a região do infravermelho (IV), que é responsável pela radiação térmica e seu intervalo de comprimento de onda está entre 780 a $2500 \mathrm{~nm}$, representando cerca de $43 \%$ do espectro (FERREIRA, 2003).

\subsection{CLASSIFICAÇÃO DA MORFOLOGIA URBANA}

Segundo Stewart e Oke (2012), as Zonas Climáticas Locais (LCZ) são áreas com uma estrutura urbana de construção, inúmeros tipos de materiais e diversos tipos de uso do solo no meio 


\title{
Revista Científica ANAP Brasil
}

\author{
ISSN 1984-3240 - Volume 13, número 29, 2020
}

ambiente provenientes de atividades humanas. A LCZ é determinada conforme a temperatura da superfície seca, com a atmosfera tranquila, noites claras em zonas com relevo suave e devem possuir um diâmetro mínimo de 400 m a 1000 m (STEWART \& OKE, 2012).

O método proposto representa um sistema separado em dezessete Zonas Climáticas Locais (LCZ's) padronizadas, sendo dez estabelecidas pela tipologia da construção do solo, conforme apresentada no Quadro 1; e sete tipos de coberturas do solo (STEWART \& OKE, 2012). O método sugere que a intensidade dos focos de calor seja avaliada pela diferença de temperatura entre as LCZ'S e não pela diferença entre rural e urbano.

Quadro 1: Tipologia de cobertura de construção - LCZ

\begin{tabular}{|c|c|}
\hline Tipologia da Construção & Descrição \\
\hline 1. Maciço de edifícios altos & $\begin{array}{l}\text { Densa mistura de edifícios altos. Poucas ou nenhuma } \\
\text { árvore. Cobertura do solo é principalmente } \\
\text { pavimentada. Materiais de construção de concreto, } \\
\text { aço, pedra e vidro. }\end{array}$ \\
\hline 2. Maciço de edifícios médios & $\begin{array}{l}\text { Mistura densa de edifícios médios (3-9 pavimentos). } \\
\text { Poucas ou nenhuma árvore. Cobertura do solo é } \\
\text { principalmente pavimentada. Materiais de construção } \\
\text { de pedras, tijolos, ladrilhos e concreto. }\end{array}$ \\
\hline 3. Maciço de edifícios baixos & $\begin{array}{l}\text { Densa mistura de prédios baixos ( } 1-3 \text { pavimentos). } \\
\text { Poucas ou nenhuma árvore. Cobertura do solo } \\
\text { principalmente pavimentada. Materiais de construção } \\
\text { de pedras, tijolo, ladrilhos e concreto. }\end{array}$ \\
\hline 4. Espaço aberto com edifícios altos & $\begin{array}{l}\text { Arranjo aberto de edifícios altos. Abundância de } \\
\text { cobertura de solo permeável (plantas baixas, árvores } \\
\text { dispersas). Materiais de construção de concreto, aço, } \\
\text { pedra e vidro. }\end{array}$ \\
\hline 5. Espaço aberto com edifícios médios & $\begin{array}{l}\text { Arranjo aberto de edifícios médio (3-9 pavimentos). } \\
\text { Abundância de cobertura de solo permeável (plantas } \\
\text { baixas, árvores dispersas). Materiais de construção de } \\
\text { concreto, aço, pedra e vidro. }\end{array}$ \\
\hline 6. Espaço aberto com edifícios baixos & $\begin{array}{l}\text { Arranjo aberto de edifícios baixos (1-3 pavimentos). } \\
\text { Abundância de cobertura de solo permeável (plantas } \\
\text { baixas, árvores dispersas). Materiais de construção de } \\
\text { madeira, tijolo, pedras, telhas e concreto. }\end{array}$ \\
\hline 7. Adensamento de edifícios baixos & $\begin{array}{l}\text { Densa mistura de edifícios baixos. Poucas ou nenhuma } \\
\text { árvore. A cobertura de solo exposto. Materiais de } \\
\text { construção leve (por exemplo, madeira, palha e metal) }\end{array}$ \\
\hline 8. Grandes edifícios baixos, galpões & $\begin{array}{l}\text { Arranjo aberto de grandes edifícios baixos (1-3 } \\
\text { pavimentos). Poucas ou nenhuma árvore. Cobertura de } \\
\text { do solo principalmente pavimentada. Materiais de } \\
\text { construção de aço, concreto, metal e pedra. }\end{array}$ \\
\hline 9. Escassamente construído & $\begin{array}{l}\text { Arranjo com pequenos ou médios edifícios em um } \\
\text { ambiente natural. Abundância de cobertura de solo } \\
\text { permeável (plantas baixas, árvores dispersas). }\end{array}$ \\
\hline 10. Indústria pesada & $\begin{array}{l}\text { Estruturas industriais de baixo gabarito e de médio } \\
\text { alcance (torres, tanques, pilhas). Poucas ou nenhuma } \\
\text { árvore e cobertura pavimentada. }\end{array}$ \\
\hline
\end{tabular}

Fonte: Adaptado de Stewart e Oke (2012, p. 33).

\section{MATERIAIS E MÉTODOS}

A pesquisa foi segmentada em quatro etapas principais:

- Delimitação da área de estudo; 


\section{Revista Científica ANAP Brasil}

\section{ISSN 1984-3240 - Volume 13, número 29, 2020}

- Classificação das áreas de acordo com a metodologia das Zonas Climáticas Locais;

- Coleta de dados;

- Análise de dados.

Na Figura 1 está apresentado através do fluxograma, as principais etapas da pesquisa e as variáveis de estudo.

Figura 1: Fluxograma da pesquisa

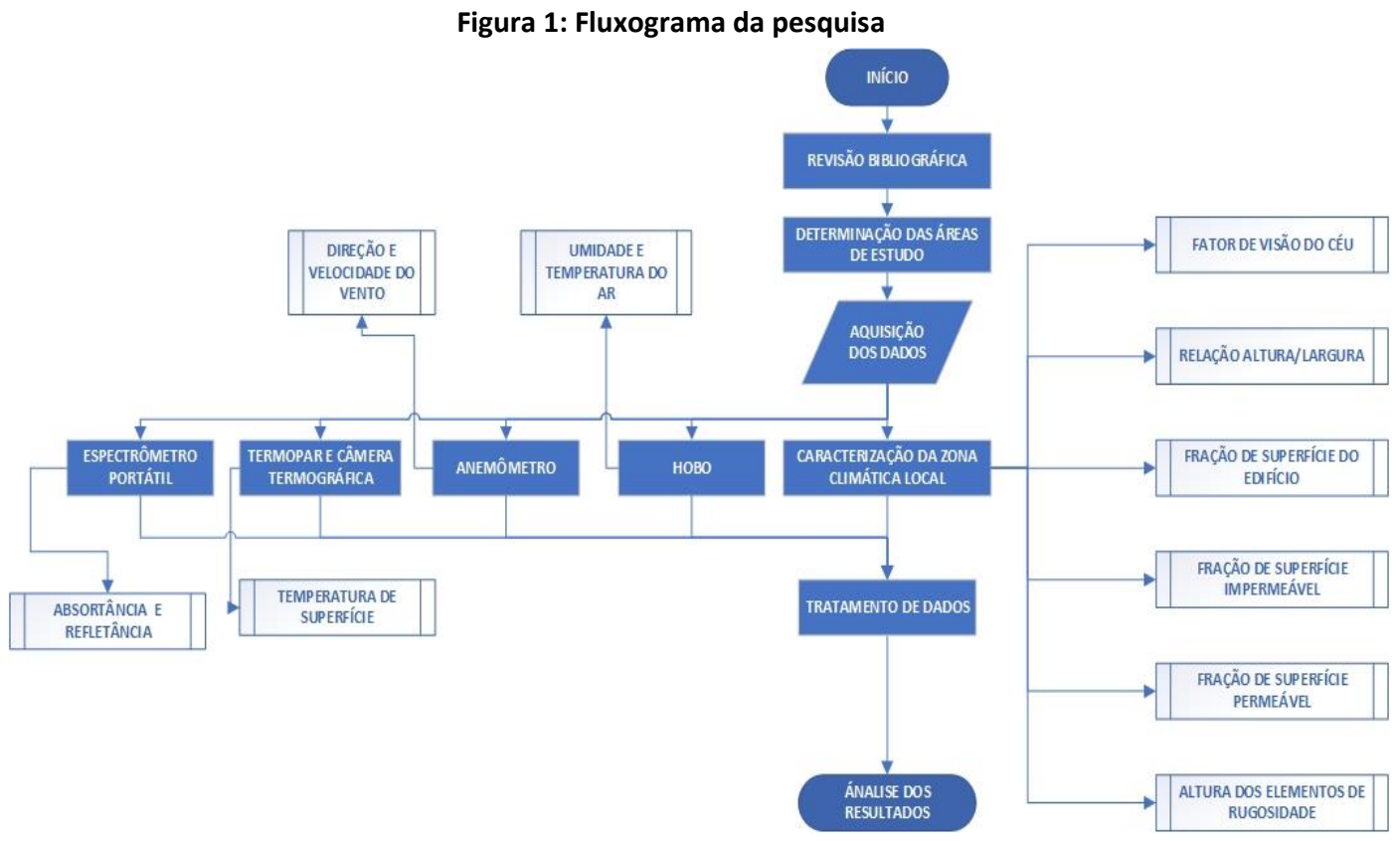

Fonte: Os autores, 2020.

\subsection{DELIMITAÇÃO DA ÁREA DE ESTUDO}

Engenheiro Coelho encontra-se no território sudeste do Brasil, no estado de São Paulo a $160 \mathrm{~km}$ da capital. Conforme o Instituto Brasileiro de Geografia e Estatística (2017) a região possui uma altitude de 655 metros e uma área de 109,8 km² com uma população estimada de 20.284 habitantes. A região apresenta verões longos e abafados e inverno curto e agradável.

O primeiro local é um recorte do pavimento asfáltico pertencente ao Condomínio Lagoa Bonita,

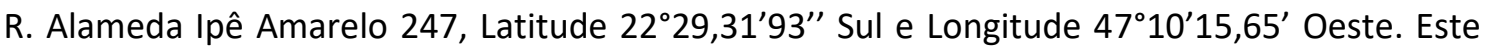
local apresenta uma densidade de construções abertas, cobertura vegetal e solo permeável conforme ilustrado na Figura 2.

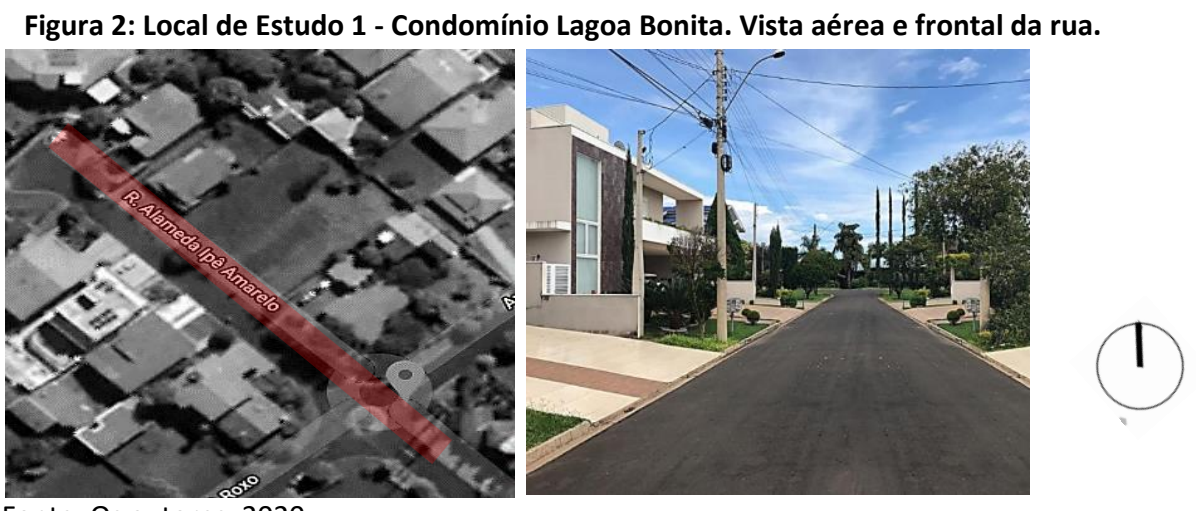




\title{
Revista Científica ANAP Brasil
}

\author{
ISSN 1984-3240 - Volume 13, número 29, 2020
}

O segundo local é um recorte do pavimento asfáltico no Condomínio Jacarandá, R. Francisco Regiani 225 , Latitude $22^{\circ} 28^{\prime} 31,32^{\prime \prime}$ Sul e Longitude $47^{\circ} 9^{\prime} 35,04^{\prime \prime}$ Oeste. Este local exibe uma densidade inferior de construções, cobertura vegetal natural e, consequentemente, um menor sombreamento se comparado ao condomínio Lagoa Bonita de acordo com a Figura 3.

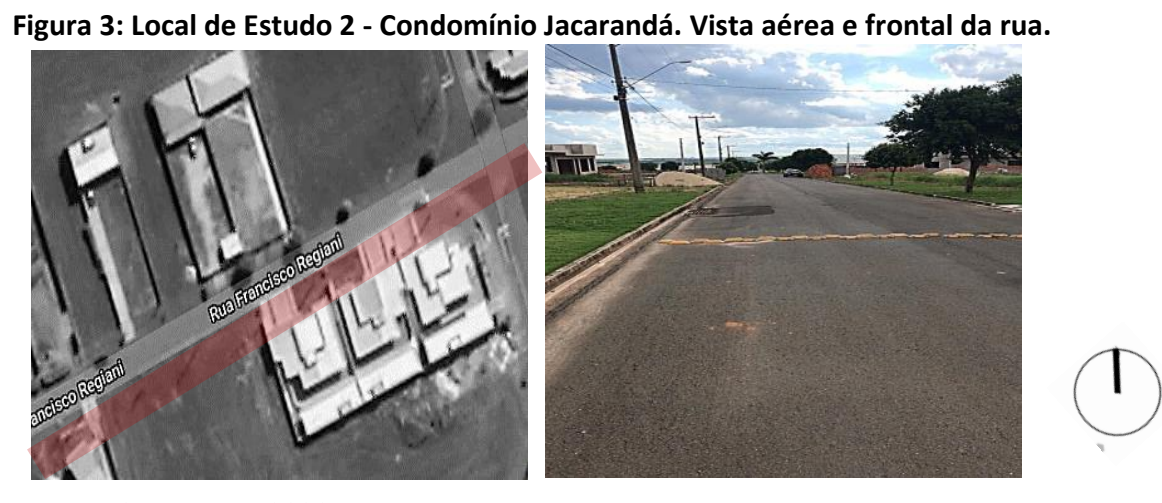

\subsection{CLASSIFICAÇÃO LCZ}

Para a classificação da LCZ, conforme o método de Stewart e Oke (2012), foi delimitada uma região com um diâmetro de $400 \mathrm{~m}$ em relação ao ponto de coleta de dados. O método leva em consideração parâmetros da morfologia urbana, como: Fração de superfície permeável (S.P), Impermeável (S.I) e Edificada (S.E), Fator de Visão do Céu (FVC), Relação (H/W), a qual consiste na razão entre a Altura média das edificações $(H)$ e a Largura média nas seções da via $(W)$ e a Altura dos Elementos de Rugosidade (A.E.R).

\subsection{COLETA DE DADOS}

O experimento ocorreu durante a estação do verão. Para a realização da pesquisa, no local foram instalados os seguintes equipamentos em cada condomínio:

- Anemômetro com sua biruta orientada para o norte;

- Termo - Higrômetro НОВО a uma altura de $200 \mathrm{~cm}$ em relação a superfície pavimentada;

- 05 sensores de temperatura superficial DS18b20 Tipo Sonda conectados a caixa coletora de dados JVI na superfície de cada pavimento asfáltico em distâncias pré-determinadas, conforme ilustrado na Figura 4.

Figura 4: Instalação dos sensores para coleta de temperatura superficial

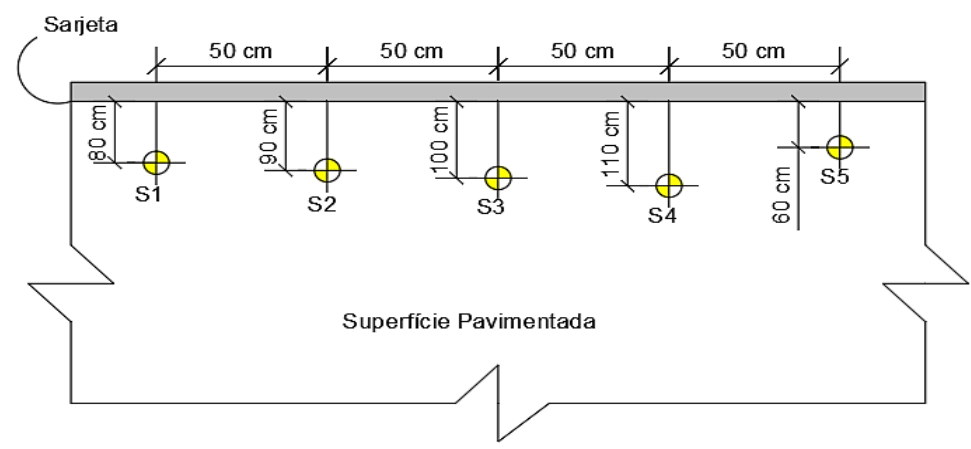

Fonte: Os autores, 2020. 


\section{Revista Científica ANAP Brasil}

\section{ISSN 1984-3240 - Volume 13, número 29, 2020}

A coleta de dados de temperatura superficial será realizada através de termopares de forma automática com um intervalo de coleta de 1 minuto. Toda a etapa de instrumentação foi realizada durante em dias de céu aberto e vento fraco (velocidade inferior à $2 \mathrm{~m} / \mathrm{s}$ ). No Quadro 2 está apresentada a relação de equipamentos utilizados na pesquisa, bem como as variáveis de estudo.

\begin{tabular}{|c|c|c|}
\hline \multicolumn{3}{|c|}{ Quadro 2: Relação de equipamentos e variáveis de estudo } \\
\hline Equipamentos & Marca/Modelo & Variáveis \\
\hline 10 sensores de temperatura & DS 18b20 Tipo Sonda & Temperatura superficial $\left({ }^{\circ} \mathrm{C}\right)$ \\
\hline Anemômetro & Anemômetro em Alumínio & Velocidade $(\mathrm{km} / \mathrm{h})$ e Direção do Vento $\left({ }^{\circ}\right)$ \\
\hline Datalogger & $\begin{array}{l}\text { Microcontrolador Esp32(wroom) - } \\
\text { Coletor de Dados JVI }\end{array}$ & Caixa coletora de dados \\
\hline Espectrômetro Portátil & Lunar and Planetary Institute/ ALTA II & Refletância $(\rho)$ e Absortância $(\alpha)$ \\
\hline Termo-Higrômetro & HOBO Pro V2 U23-001 & $\begin{array}{l}\text { Umidade Relativa (\%) e Temperatura do } \\
\qquad \operatorname{ar}\left({ }^{\circ} \mathrm{C}\right)\end{array}$ \\
\hline WRPLOT View & Lakes Environmental & Direção dos ventos predominantes \\
\hline
\end{tabular}

Fonte: Os autores, 2020.

Por fim, na caracterização do albedo do pavimento, será utilizado o espectrômetro portátil ALTA II respeitando a metodologia proposta por Muniz-Gäal, et al. (2018). No tratamento de dados de vendo será utilizado o software WRPlot View, a fim de determinar a direção do vento predominante.

\section{ANÁLISE DE RESULTADOS}

A análise de resultados desta pesquisa busca relacionar as características do traçado urbano às propriedades térmicas da superfície pavimentada em dois locais de estudo, com o intuito de identificar se há alguma influência direta da classificação das Zonas Climáticas Locais na temperatura superficial dos pavimentos.

Para isso, a justificativa dos resultados está embasada na caracterização microclimática do local, relacionando a umidade relativa, velocidade e direção do vento às variações térmicas do pavimento asfáltico.

\subsection{CARACTERIZAÇÃO DO RECORTE NO CONDOMÍNIO LAGOA BONITA}

Na Figura 5 é apresentada a velocidade de vento mais frequente no período de coleta e a direção do vento dominante no Lagoa Bonita. Que contribui na análise do fluxo de ar.

Figura 5: Vento predominante - Condomínio Lagoa Bonita

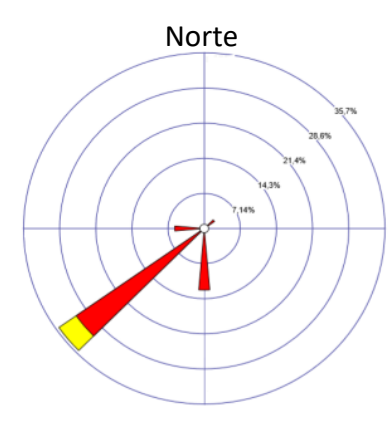

Fonte: Os autores, 2020.

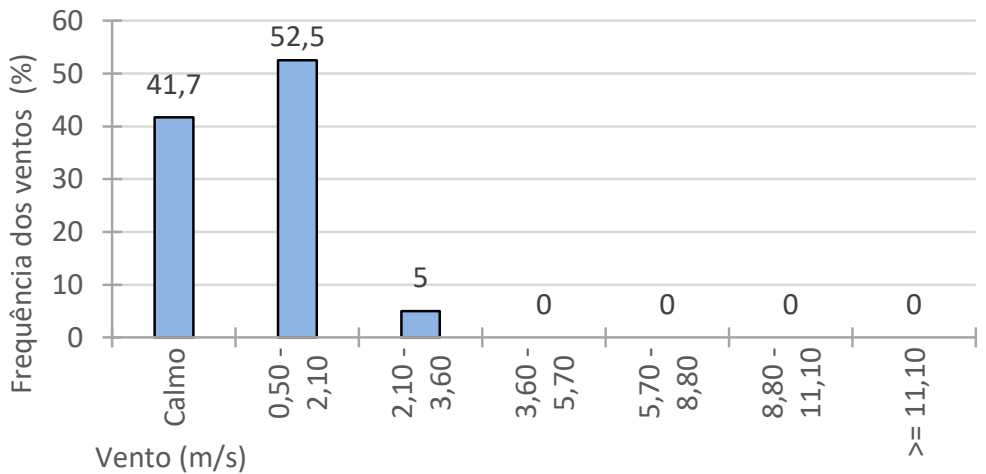

Vento $(\mathrm{m} / \mathrm{s})$ 


\title{
Revista Científica ANAP Brasil
}

\author{
ISSN 1984-3240 - Volume 13, número 29, 2020
}

A orientação geográfica da Rua Ipê Amarelo está posicionada no sentido sudeste. A direção do vento dominante no dia da coleta, conforme apresentado na Figura 5 , incide a sudoeste, ou seja, perpendicularmente à seção do recorte urbano e com velocidade de 0,5 a 2,10 m/s. Esses ventos ocorreram com $52,5 \%$ de frequência durante o período.

O fluxo de ar que passa sobre o topo do recorte impede que a radiação de onda longa, emitida pelas superfícies seja dissipada para atmosfera, o que provoca um acúmulo de calor e que, por consequência, interfere nas condições de conforto no nível do pedestre.

No entanto, existe um vazio na parte lateral direita do recorte. Este espaço vago permite que uma parte da corrente de ar se dissipe no ambiente e uma porção do calor acumulado seja perdido.

A classificação do recorte urbano segundo a metodologia proposta por Stewart e Oke (2012), propõe o levantando de parâmetros como o fator de visão do céu, relação H/W, distribuição das áreas permeável, impermeável e edificada. Esses parâmetros referentes ao Condomínio Lagoa Bonita estão agrupados na Figura 6.

Figura 6: Parâmetros de Estudo - Classificação LCZ - Condomínio Lagoa Bonita

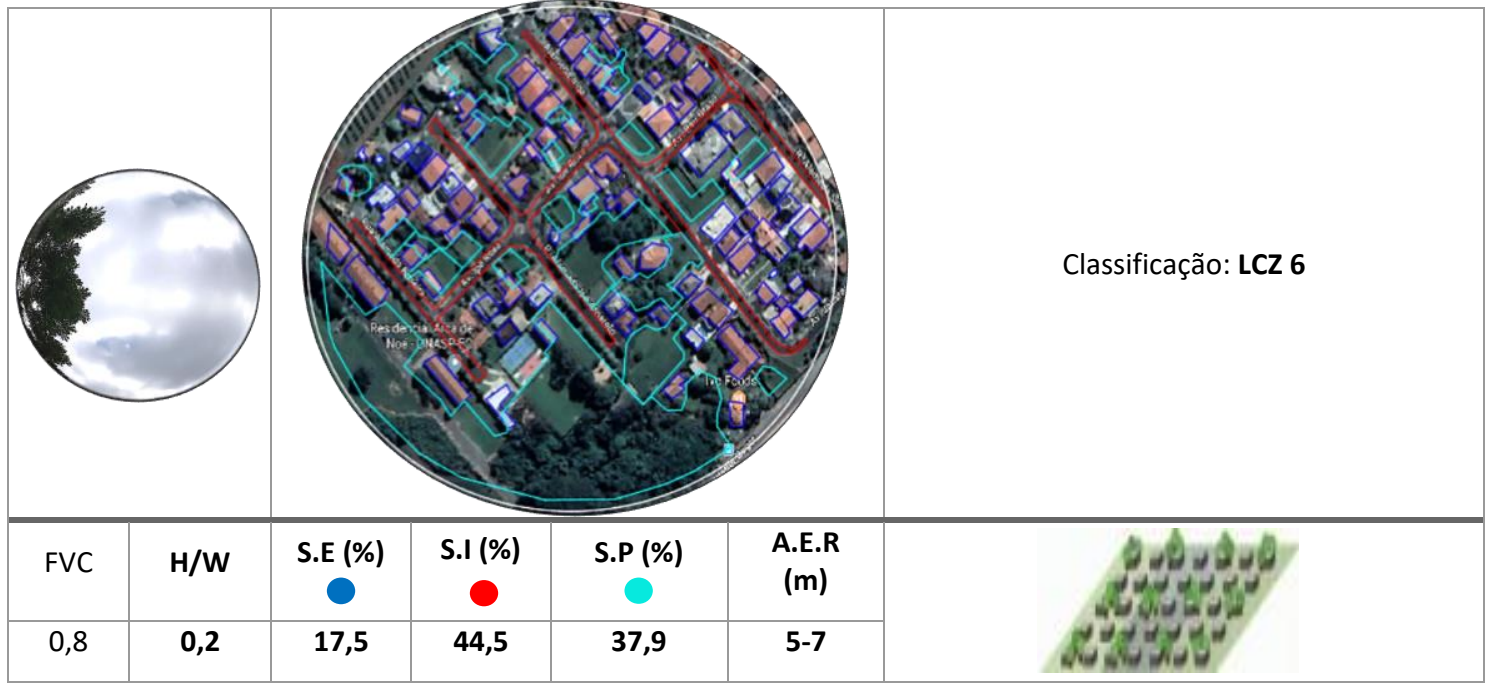

Fonte: Os autores, 2020.

A área delimitada para estudo no Condomínio Lagoa Bonita apresenta uma disposição construtiva aberta com edificações baixas e com recuo frontal. As construções têm cerca de 5 a 7 metros de altura e representam 17,5\% de superfície edificada no ambiente delimitado.

Mesmo tendo uma área impermeável notável de 44,5\%, sua cobertura vegetal é considerável, representando $37,9 \%$ de área permeável com plantas baixas e árvores espalhadas pelo local. Seguindo os parâmetros sugerido por Stewart \& Oke (2012) essa zona climática se assemelha a LCZ 6.

\subsection{CARACTERIZAÇÃO DO RECORTE NO CONDOMÍNIO JACARANDÁ}

Na Figura 7 é apresentada a velocidade de vento mais frequente no período de coleta e a direção do vento dominante no Lagoa Bonita, que contribuir na análise do sentido do fluxo de ar no cânion urbano desse recorte. 


\section{Revista Científica ANAP Brasil}

ISSN 1984-3240 - Volume 13, número 29, 2020

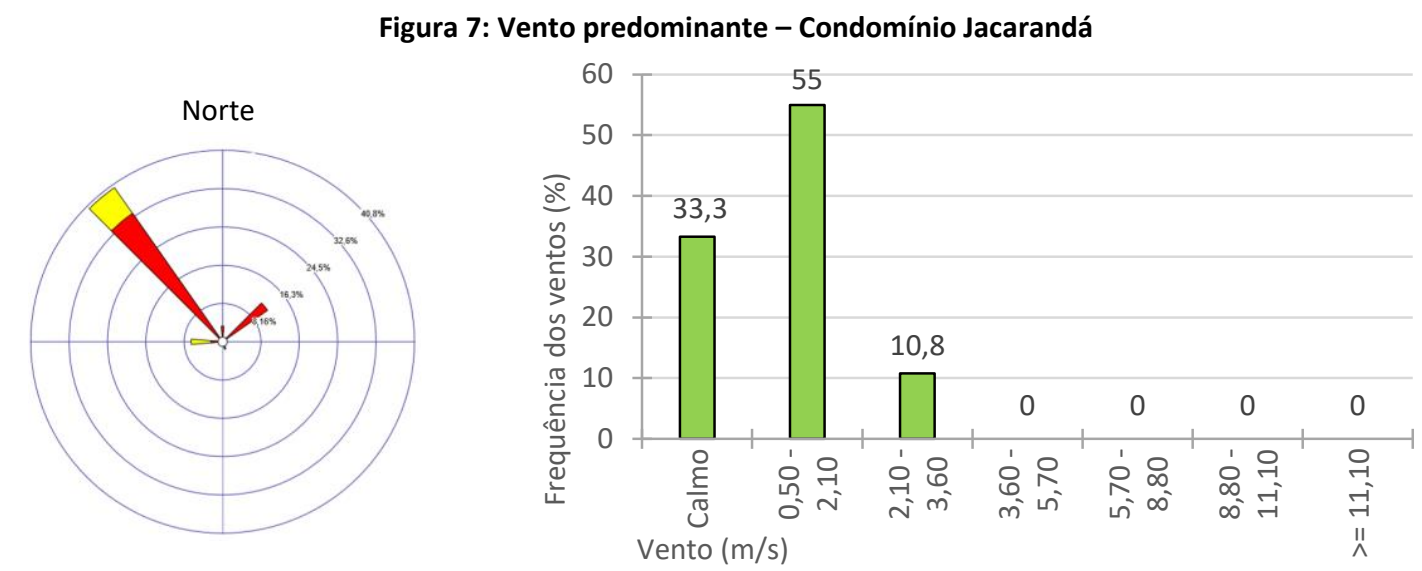

Fonte: Os autores, 2020.

A Rua Francisco Regiani, situada no Condomínio Jacarandá, está orientada a sudoeste. Nos dias da coleta, o vento predominante registrado pelo anemômetro neste local incide a noroeste, ou seja, perpendicularmente à seção do cânion, provocando o mesmo efeito térmico que no Condomínio Lagoa Bonita, a frequência que os ventos de 0,50 a 2,10 m/s ocorrerem no local foi de $55 \%$ do tempo da coleta.

Devido a uma menor densidade construtiva e uma maior quantidade de espaços vazios, há uma maior dissipação do calor. Pelo fato do fluxo de ar se encaminhar aos espaços vagos e não ter construções para reter esta massa de ar quente.

Entretanto, existe uma outra hipótese: se os ventos dominantes estivessem passando paralelos à seção do recorte, a radiação emitida pelas superfícies seria carregada pelo fluxo de ar, o que favoreceria a dissipação do calor juntamente com os espaços vazios.

A classificação do recorte urbano segundo a metodologia proposta por Stewart e Oke (2012), propõe o levantando de parâmetros como o fator de visão do céu, relação H/W, distribuição das áreas permeável, impermeável e edificada. Esses parâmetros referentes ao Condomínio Jacarandá estão agrupados na Figura 8. 


\section{Revista Científica ANAP Brasil}

\section{ISSN 1984-3240 - Volume 13, número 29, 2020}

Figura 8: Parâmetros de Estudo - Classificação LCZ - Condomínio Jacarandá

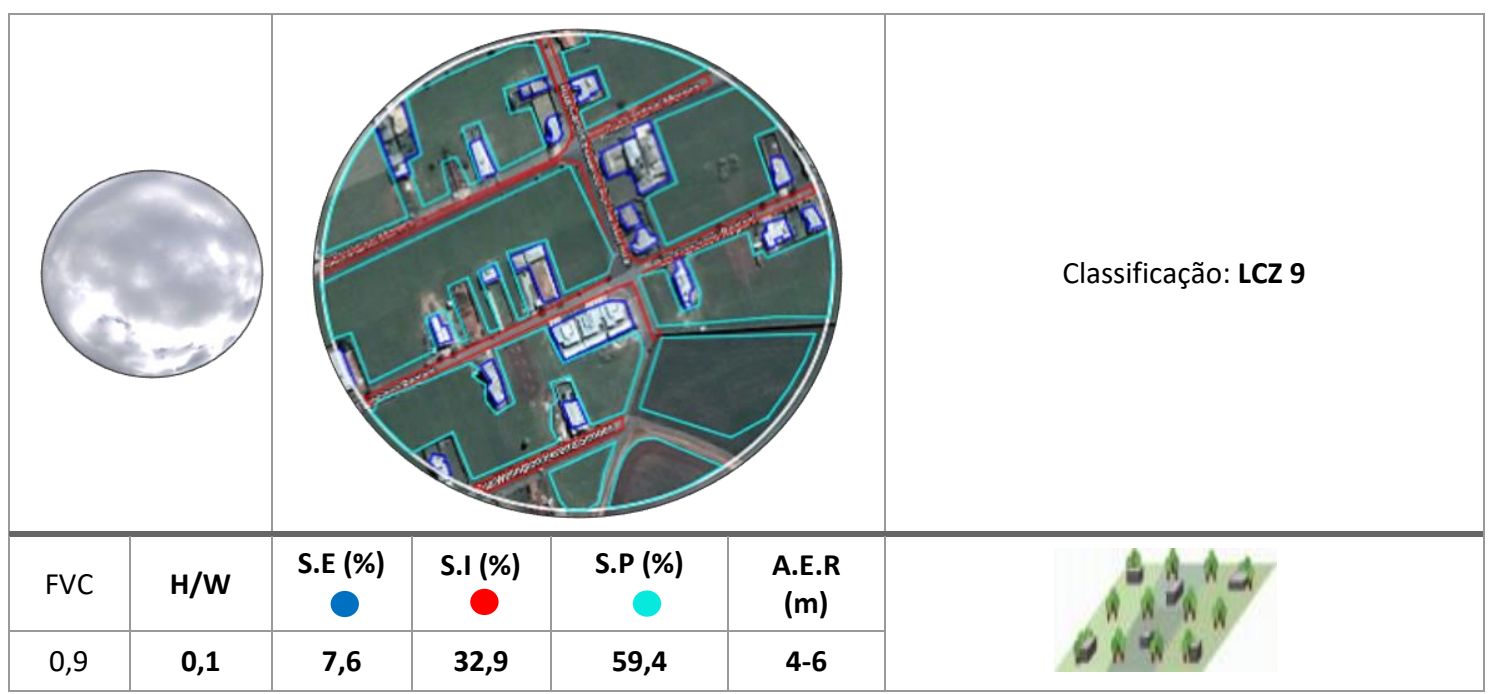

Fonte: Os autores, 2020.

A área demarcada no Condomínio Jacarandá apresenta uma distribuição construtiva mais aberta e espalhada que o Lagoa Bonita. Suas edificações têm cerca de 4 a 6 metros de altura e uma superfície edificada com cerca de 7,6\%.

Sua cobertura vegetal rasteira é mais abundante em relação ao Lagoa Bonita, representando cerca de 59,4\% da superfície permeável, com plantas baixas e pouquíssimas árvores distribuídas pelo local. Seguindo os parâmetros sugeridos por Stewart \& Oke essa zona climática se assemelha a LCZ 9.

\subsection{ALBEDO DOS PAVIMENTOS}

O albedo ou a refletância solar do pavimento é uma propriedade radiante do material importante para a análise da temperatura superficial. Pois é a capacidade de refletir a radiação incidente (FERREIRA et al., 2015). O albedo pode sofrer variações em função do tipo de ligante asfáltico, da idade do pavimento e do agregado incorporado na mistura. Sendo assim, estão apresentados na Tabela 2, os valores de albedo do pavimento de ambos os locais de estudo.

Tabela 2: Propriedades radiantes dos pavimentos dos locais de estudo.

\begin{tabular}{|l|c|c|}
\hline & Jacarandá - (JAC) & Lagoa Bonita - (LAG) \\
\hline Refletância [ $\boldsymbol{\rho}]$ & 0,11 & 0,07 \\
\hline Absortância $[\boldsymbol{\alpha}]$ & 0,89 & 0,93 \\
\hline
\end{tabular}

Fonte: Os autores, 2020.

$\mathrm{Na}$ Figura 9 é apresentada a refletância espectral para cada comprimento de onda tanto na faixa do visível (VIS) até a faixa do infravermelho próximo (NIR) do pavimento das duas áreas de estudo. 


\section{Revista Científica ANAP Brasil}

\section{ISSN 1984-3240 - Volume 13, número 29, 2020}

Figura 9: Refletância espectral das superfícies asfálticas

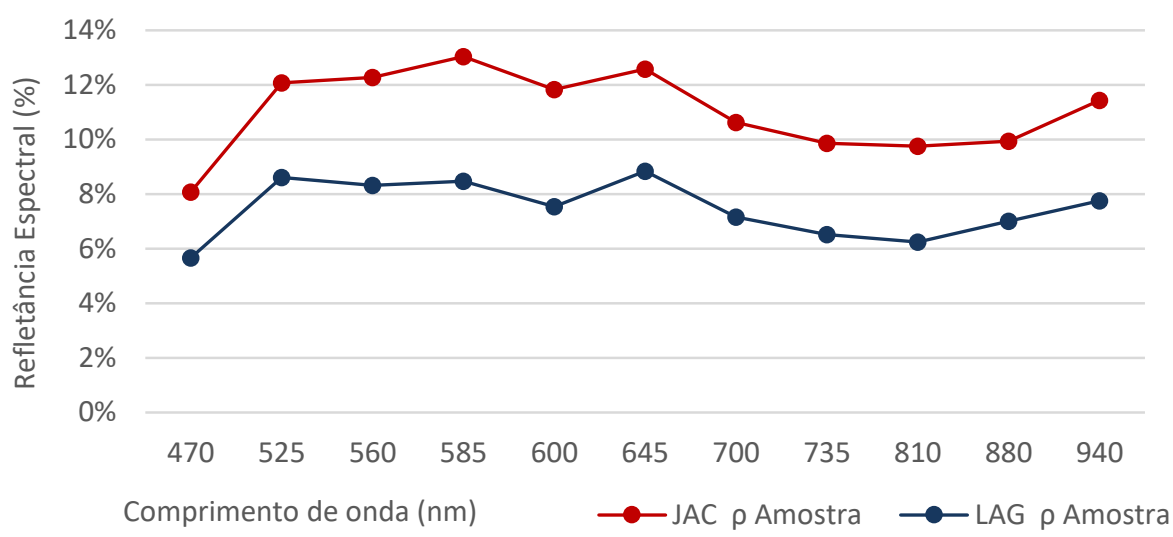

Fonte: Os autores, 2020.

Os resultados foram obtidos através de medições no local com o espectrômetro portátil ALTA II, conforme avaliado por Pereira et al. (2015) que abrange a faixa do visível e do infravermelho do espectro eletromagnético. Por meio da integração da área abaixo da curva, percebe-se que a refletância solar do pavimento do Jacarandá é superior em relação ao pavimento do Lagoa Bonita. Esse fato pode ser explicado em razão da composição da massa asfáltica ou devido ao desgaste da superfície por abrasão, acúmulo de resíduos.

\subsection{VELOCIDADE DO VENTO NO INTERIOR DA MALHA}

O fluxo de ar que incide na malha intra-urbana implica diretamente na temperatura do ar. Pelo fato de favorecer o acúmulo ou a dissipação do calor (ERELL, PEARMUTTER, WILLIAMSON, 2010). Por isso, foram avaliadas a velocidade do vento em ambos os condomínios durante o período de coleta. Os dados de velocidade média dos ventos nos recortes dos Condomínios Lagoa Bonita e Jacarandá estão apresentados na Figura 10.

Figura 10: Velocidade média dos ventos nos recortes estudados

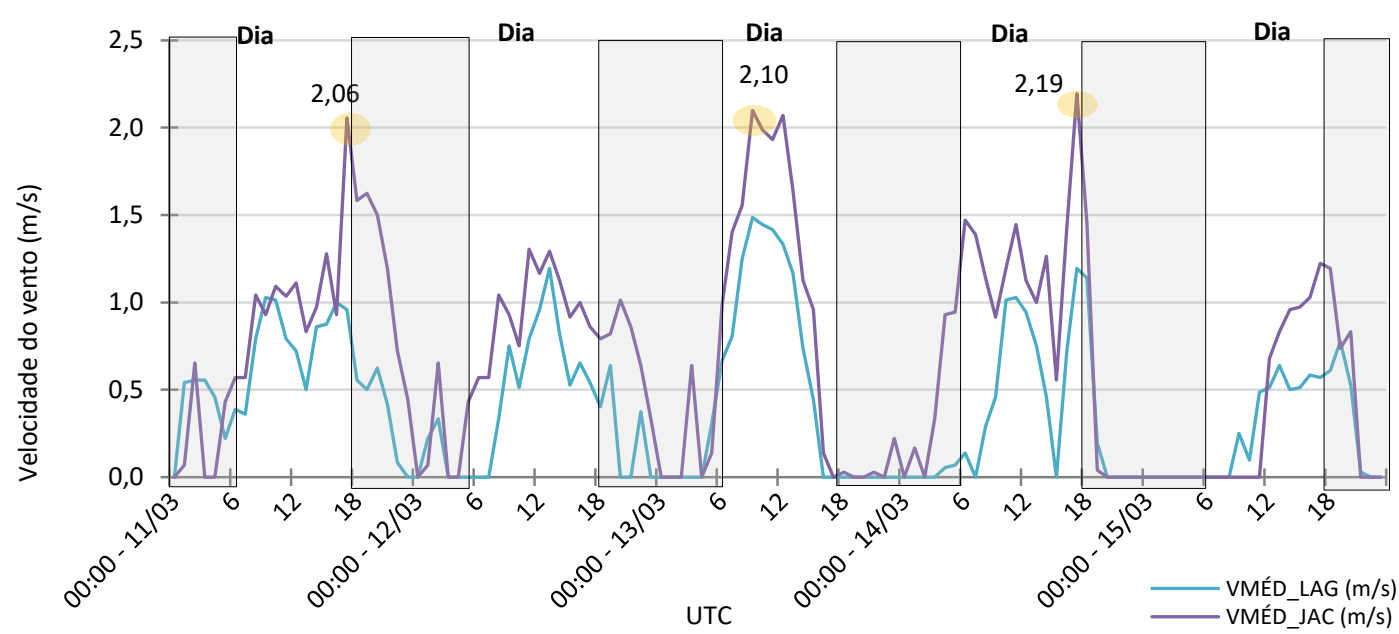

Fonte: Os autores, 2020.

Nota-se que a velocidade média horária dos ventos no recorte do Jacarandá apresentou variações de aproximadamente $1 \mathrm{~m} / \mathrm{s}$ geralmente identificadas no final da tarde em relação ao recorte do Condomínio Lagoa Bonita em todo período de coleta. A variação da velocidade do 


\section{Revista Científica ANAP Brasil}

\section{ISSN 1984-3240 - Volume 13, número 29, 2020}

vento entre os dois condomínios, que apresentam morfologias distintas, está representada na Figura 11.

Figura 11: Diferença de velocidade média dos ventos nos recortes dos Condomínios Lagoa Bonita e Jacarandá

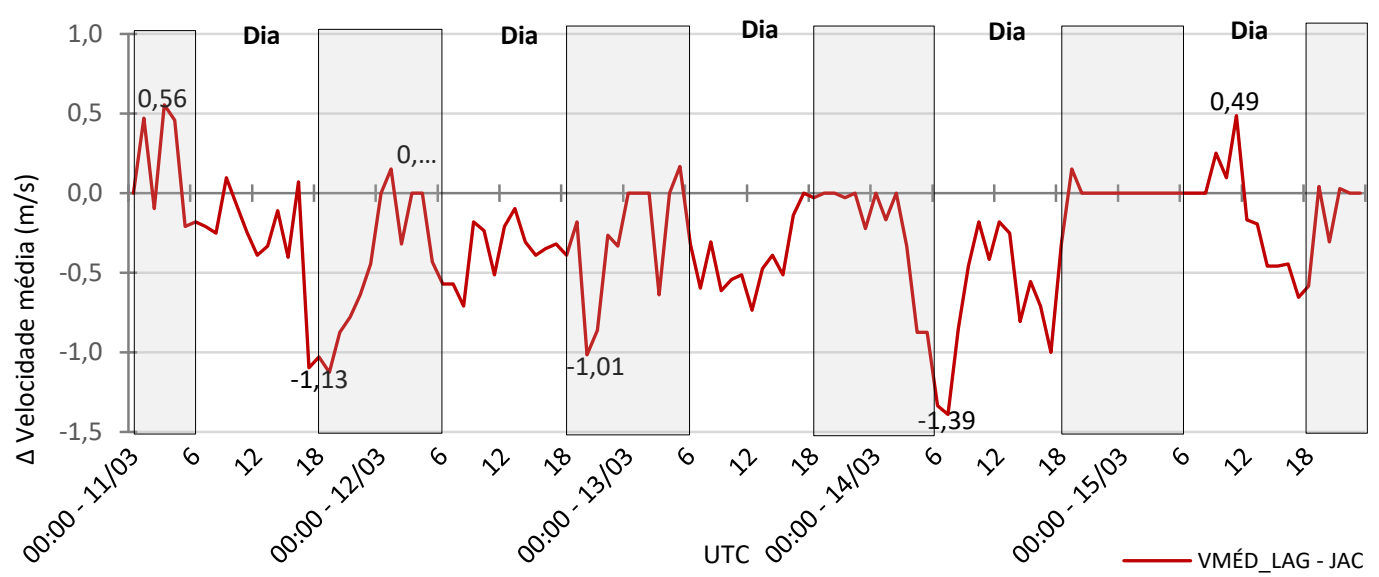

Fonte: Os autores, 2020.

Pelo fato da área demarcada no Condomínio Jacarandá ter uma maior área de campo aberto, um menor adensamento de edificações, pouca massa vegetada e apresentar menos barreiras que a área delimitada no Residencial Lagoa Bonita, a circulação do fluxo de ar permite a formação de ventos com maiores velocidades por não ser influenciada por obstáculos.

\subsection{TEMPERATURA DO AR E TEMPERATURA SUPERFICIAL DO PAVIMENTO}

A temperatura do ar e a temperatura superficial são variáveis importantes para avaliação do microclima local. Pois estão relacionadas ao material de cobertura e composição da paisagem urbana. Na Figura 12 é apresentada uma comparação da temperatura superficial do pavimento com a do ar dos Condomínios Lagoa Bonita e Jacarandá.

Figura 12: Temperatura superficial dos pavimentos e do ar - Lagoa Bonita e Jacarandá

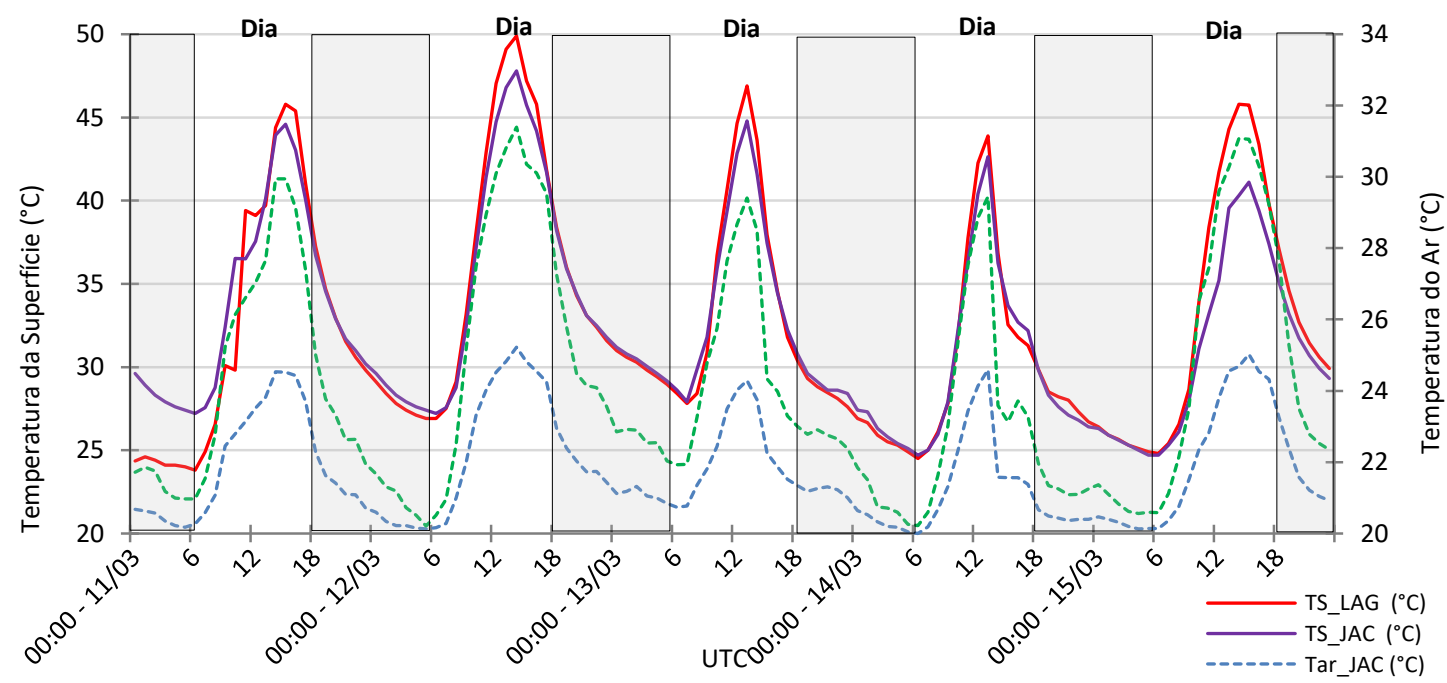

Fonte: Autores, 2020.

Percebe-se tanta a temperatura superficial do Lagoa Bonita é superior em relação ao condomínio Jacarandá durante o instante do meio-dia. Além disso, nota-se que tanto a 


\title{
Revista Científica ANAP Brasil
}

\author{
ISSN 1984-3240 - Volume 13, número 29, 2020
}

temperatura superficial, quanto do ar, em boa parte dos dias se equaliza por volta das 06 horas da manhã. Na Figura 13 são apresentadas as variações de temperatura entre os condomínios.

Figura 13: Variação da temperatura entre o Lagoa Bonita e Jacarandá

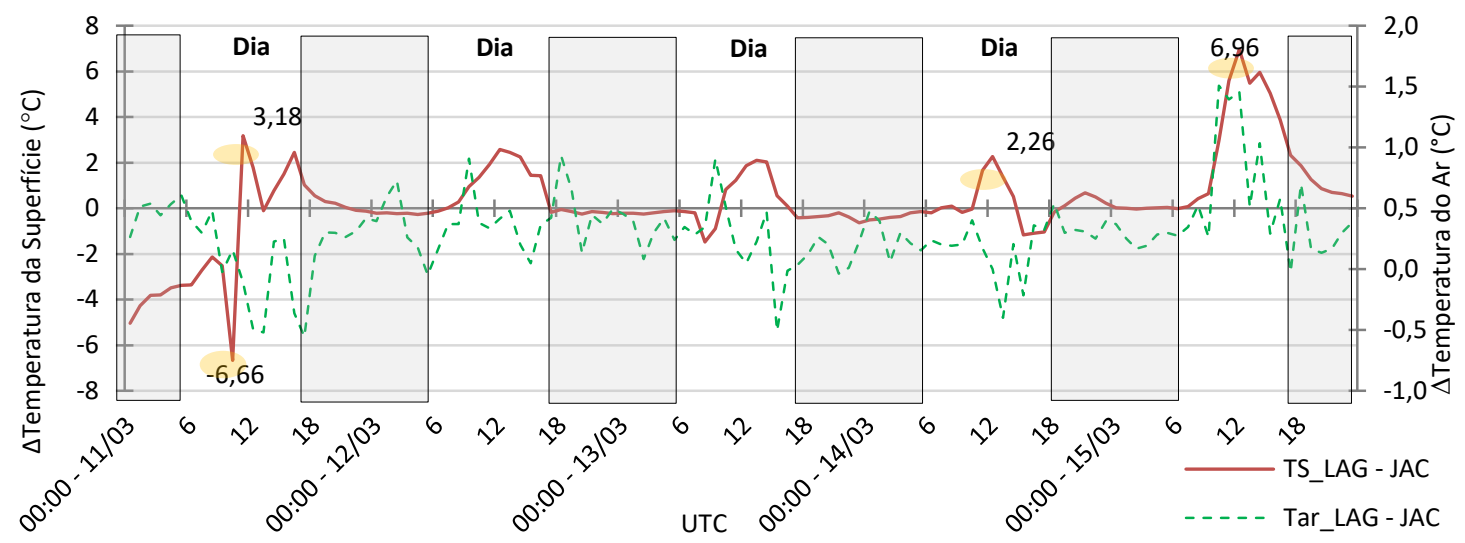

Fonte: Autores, 2020.

Percebe-se que a temperatura de superfície do recorte no Lagoa Bonita é superior em relação ao Jacarandá, porém, essa variação de temperatura entre os dois locais é mais marcante durante o período do dia.

A temperatura de superfície no Lagoa Bonita é superior em relação ao Jacarandá, apresentando uma maior variação máxima durante o período diurno de aproximadamente $2^{\circ} \mathrm{C}$. Apesar de 0 Lagoa Bonita ter uma maior taxa de superfície vegetada e sombreada, esses registros de temperatura são justificados pelo maior adensamento de edificações e absorção do pavimento asfáltico, que faz com que haja um acúmulo de calor na malha intra-urbana.

No dia 15 de março, próximo ao horário do meio-dia, houve uma variação máxima atípica de aproximadamente $7^{\circ} \mathrm{C}$. Esse fato pode ser explicado em virtude da menor velocidade média do vento registrada em relação a todo período de coleta.

\section{CONSIDERAÇÕES FINAIS}

Este trabalho analisou a influência da morfologia urbana, na temperatura do ambiente de um recorte espacial em dois condomínios no município de Engenheiro Coelho - SP considerando variáveis climáticas: Temperatura de superfície e ar, umidade relativa do ar e velocidade e direção do vento.

Pode-se afirmar que os ventos dominantes em ambos os condomínios passam perpendicularmente nas direções sudoeste e noroeste dos recortes. Logo, o calor fica retido tanto no ar como na superfície. O recorte estudado no condomínio Jacarandá não possui uma forma bem definida. No local existem muitos espaços vazios e uma frequência de ventos mais elevada, assim o calor tende a se dissipar, registrando temperaturas superficiais menores.

No recorte do Lagoa Bonita o albedo do pavimento é menor, quando comparado ao condomínio Jacarandá. Desta forma, absorvem mais calor, devido à coloração mais escura, o que implicam em uma temperatura superficial do pavimento mais elevada se comparada ao Jacarandá. 


\title{
Revista Científica ANAP Brasil
}

\author{
ISSN 1984-3240 - Volume 13, número 29, 2020
}

Os resultados obtidos demonstraram que no recorte Condomínio Lagoa Bonita apresenta valores superiores na temperatura superficial em relação ao recorte do Condomínio Jacarandá. Há uma variação média de $2^{\circ} \mathrm{C}$, com valores máximos registrados de aproximadamente $7^{\circ} \mathrm{C} \mathrm{em}$ dias de vento fraco. Esse fato pode ser explicado, devido à baixa velocidade do vento causada pela turbulência na malha interurbana, que é mais intensa no recorte do condomínio com maior adensamento, no caso o Lagoa Bonita.

A velocidade no recorte do Condomínio Jacarandá apresentou registros de até $1,0 \mathrm{~m} / \mathrm{s}$ a mais do que o Lagoa Bonita, por conta da rugosidade da malha, em função da altura média das edificações e dos elementos que compõe esse recorte.

A temperatura do ar no recorte do Jacarandá apresentou uma diferença de aproximadamente $0,5^{\circ} \mathrm{C}$ superior ao Lagoa Bonita. Em relação à umidade relativa no recorte do Condomínio Lagoa Bonita, os valores registrados foram cerca de $6 \%$ superiores, devido à maior quantidade de cobertura vegetada.

Com o modelo de Stewart \& Oke, pode-se chegar à conclusão de que na LCZ 6 a temperatura superficial no interior da malha urbana, é superior em relação à LCZ 9. Esse fato pode ser explicado devido a maior quantidade de superfície impermeável e edificada.

A LCZ 9 apresenta uma maior intensidade de ventos, um pavimento com maior albedo, porém apresenta poucos elementos de sombreamento o que torna um ambiente com condições térmicas menos favoráveis.

Por fim, entende-se que este trabalho pode colaborar, de maneira inicial, com outras pesquisas que venham a utilizar a metodologia de Zonas Climáticas Locais desenvolvida por Stewart \& Oke em um contexto de clima tropical.

\section{AGRADECIMENTOS}

Agradecemos ao Centro Universitário Adventista de São Paulo (UNASP) ao ceder as instalações do laboratório de conforto do Núcleo de Tecnologia de Engenharias e Arquitetura (NUTEA) e à Universidade Federal de São Carlos (UFSCar) pelo suporte na etapa de instrumentação e coleta de dados.

\section{REFERÊNCIAS BIBLIOGRÁFICAS}

AYOADE, J. O. Introdução à climatologia para trópicos. Rio de janeiro: Bertrand Brasil, 1991. 332p.

CORBELLA, O. D. Ã.; MAGALHÃES, M. A. A. A. Conceptual differences between the bioclimatic urbanism for Europe and for the tropical humid climate. Renewable Energy, v. 33, p. 1019-1023, 2008.

DORNELLES, K. A. Absortância solar de superfícies opacas: métodos de determinação e base de dados para tintas látex acrílica e PVA. 2008. 160p. Tese (Doutorado) - Faculdade de Engenharia Civil, Arquitetura e Urbanismo, Universidade Estadual de Campinas, Campinas, 2008.

ERELL, E.; PEARLMUTTER, D.; WILLIAMSON, T. Urban Microclimate: Designing the Space Between Buildings. London, 2010: Earthscan/James \& James Science Publishers p.266.

FERREIRA, F. L., PRADO, R. T. A. Medição do albedo e análise da sua influência na temperatura superficial dos materiais utilizados em coberturas de edifícios no Brasil. Boletim Técnico da Escola Politécnica da USP, 2003. 


\title{
Revista Científica ANAP Brasil
}

\author{
ISSN 1984-3240 - Volume 13, número 29, 2020
}

FRANCO, F. M. Análise do comportamento termo-higrométrico urbano sob a ótica do uso e ocupação do solo em Cuiabá-MT. 2013, 124f. Tese (Doutorado em Física Ambiental), Instituto de Física, Universidade Federal de Mato Grosso, Cuiabá, 2013.

GARTLAND, L. Ilhas de calor: como mitigar zonas de calor em áreas urbanas. São Paulo: Oficina de Textos, 2010.

GHENO, E. L. Variações Microclimáticas na Área Urbana de Sinop / MT no final da estação chuvosa. Educação, Cultura e Sociedade, v. 2, p. 139-153, 2012.

INSTITUTO BRASILEIRO DE GEOGRAFIA E ESTATÍSTICA. Classificação e caracterização dos espaços rurais e urbanos do Brasil: uma primeira aproximação. Rio de Janeiro: 2017.

MONTEIRO, V. S. Zonas Climáticas Locais e a relação com a morfologia urbana. Estudo de caso: Campinas/SP. 2018, 167f. Dissertação de mestrado. Pontifícia Universidade Católica de Campinas, Campinas, SP, Brasil, 2018.

MENDONÇA, F; DANNI-OLIVEIRA, I M. Climatologia: noções básicas e climas do Brasil. São Paulo: Oficina de texto, 2007.

MUNIZ-GÄAL, L. P.; PEZZUTO, C. C.; CARVALHO, M. F. H. de; MOTA, L. T. M. Eficiência térmica de materiais de cobertura. Ambiente Construído, Porto Alegre, v. 18, n. 1, p. 503-518, jan./mar. 2018.

NETO, R. X. DE M. Temperatura da Superfície nos Materiais de Pavimentação: uma contribuição ao desenvolvimento urbano. 2015, 159f. Dissertação (Mestrado). Universidade Federal de Pernambuco, Pernambuco, 2015.

PEREIRA, C. D.; MARINOSKI, D. L.; LAMBERTS, R.; et al. Guia de medição e cálculo para refletância e absortância solar em superfícies opacas (v.1). Florianópolis: UFSC, 2015.

STEWART, I. D.; OKE, T. R. Local climate zones for urban temperature studies. Bulletin of the American Metheorological Society, v. 93, n. 12, p. 1879-1900, 2012. 